\title{
THE
}

\section{Organophosphate Ester Flame Retardants and Plasticizers in ocean sediments from the North Pacific to the Arctic Ocean}

Yuxin Ma

Zhiyong Xie

Rainer Lohmann

University of Rhode Island, rlohmann@uri.edu

Wenying Mi

Guoping Gao

Follow this and additional works at: https://digitalcommons.uri.edu/gsofacpubs

The University of Rhode Island Faculty have made this article openly available.

Please let us know how Open Access to this research benefits you.

This is a pre-publication author manuscript of the final, published article.

Terms of Use

This article is made available under the terms and conditions applicable towards Open Access

Policy Articles, as set forth in our Terms of Use.

\section{Citation/Publisher Attribution}

Yuxin Ma, Zhiyong Xie, Rainer Lohmann, Wenying Mi, Guoping Gao. Organophosphate Ester Flame Retardants and Plasticizers in ocean sediments from the North Pacific to the Arctic Ocean. Environ Sci Technol 2017, 51, 3809-3815, DOI: 10.1021/acs.est.7b00755.

Available at: http://dx.doi.org/10.1021/acs.est.7b00755

This Article is brought to you for free and open access by the Graduate School of Oceanography at DigitalCommons@URI. It has been accepted for inclusion in Graduate School of Oceanography Faculty Publications by an authorized administrator of DigitalCommons@URI. For more information, please contact digitalcommons@etal.uri.edu. 


\section{Organophosphate Ester Flame Retardants and 2 Plasticizers in ocean sediments from the North \\ Pacific to the Arctic Ocean}

Yuxin Ma ${ }^{a, c^{*}}$, Zhiyong Xie ${ }^{b^{* *}}$, Rainer Lohmann ${ }^{c}$, Wenying Mi ${ }^{b}$, Guoping Gao ${ }^{a}$ 6

${ }^{a}$ College of Marine Sciences, Shanghai Ocean University, Shanghai 201306, China

${ }^{\mathrm{b}}$ Helmholtz-Zentrum Geesthacht, Centre for Materials and Coastal Research GmbH, Institute of Coastal Research, Max-Planck Street 1, D-21502 Geesthacht, Germany

${ }^{\mathrm{c}}$ Graduate School of Oceanography, University of Rhode Island, Narragansett, Rhode Island 02882, United States

3 * Corresponding author: phone: 401-677-9324

14 E-mail address: $\underline{\text { xinxin0709@126.com }}$

$5 *$ Corresponding author: phone: $+49-4152-872330 ;$ Fax: +49-4152-872332

6 E-mail address: zhiyong.xie@ @zzg.de 


\section{Abstract}

The occurrence of organophosphate ester (OPE) flame retardants and plasticizers has been observed for the first time in surface sediment from the North Pacific to Arctic Ocean during the 4th National Arctic Research Expedition of China in the summer of 2010. The samples were analyzed for three halogenated OPEs (tris(2-chloroethyl) phosphate (TCEP), tris(1-chloro-2-propyl) phosphate (TCPP) and tris(dichlorisopropyl) phosphate (TDCP)), three alkylated OPEs (tri-iso-butyl phosphate (TiBP), tri- $n$-butyl phosphate (TnBP) and tripentyl phosphate (TPeP)), as well as triphenyl phosphate (TPhP). $\Sigma_{7} \mathrm{OPEs}$ (total concentration of the observed OPEs) was in the range of 159 to $4658 \mathrm{pg} \mathrm{g}^{-1}$ dry weight (dw). Halogenated OPEs were generally more abundant than the non-halogenated OPEs; TCEP and TiBP dominated overall concentrations. Except for Bering Sea, $\Sigma_{7} \mathrm{OPEs}$ concentrations increased with the increasing latitudes from Bering Strait to the Central Arctic Ocean. While the contributions of halogenated OPEs (typically TCEP and TCPP) to total OPE profile also increased from Bering Strait to the Central Arctic Ocean, indicating their higher potential of being transported to the remote Arctic. The median budget of 52 (range of 17-292) tons for $\Sigma_{7}$ OPEs in sediment from the Central Arctic Ocean represents only a very small amount of their total production volume. Yet the amount of OPEs in Arctic Ocean sediment was significantly higher than the sum of polybrominated diphenylethers (PBDEs) in the sediment, indicating they are equally prone to long-range transport away from source regions. Given the increasing production and usage of OPEs as substitutes of PBDEs, OPEs will continue to 
accumulate in the remote Arctic.

\section{Introduction}

Organophosphate esters (OPEs) are kinds of man-made chemicals applied to many household and industrial products as flame retardants, plasticizers, as well as antifoaming agents and hydraulic fluids. ${ }^{1}$ Specifically, halogenated OPEs are dominantly applied as flame retardants, while non-halogenated OPEs are mainly applied as plasticizers and in other applications. ${ }^{2}$ During recent years the production and use of OPEs have increased since polybrominated diphenyl ethers (PBDEs), which is known as the most commonly used brominated flame retardants (BFRs), have been restricted in the early 2000s, especially the Penta- and Octa-BDE mixtures have been finally included in the Stockholm Convention list on Persistent Organic Pollutants (POPs) (http://www.pops.int). OPE production has increased by about 10\% between 2001 and 2006 in Western Europe. ${ }^{3}$ It is estimated that the global production of OPEs accounted for $30 \%$ of all flame retardants in $2013 .{ }^{4}$

OPEs can leach into the environment as they are additive flame retardants and do not covalently bind to the material to which they are added. The environmental occurrence of OPEs have recently been reported in a variety of environmental compartments such as indoor air, ${ }^{2}$ fresh and marine water phase, $, 5,6$ as well as fresh water and marine coastal sediments; ; 78 OPEs also enter and accumulate in marine and freshwater foodwebs. ${ }^{9}{ }^{10}$ Even though the predicted half-lives of OPEs in atmosphere ( $<2$ days) are not enough to meet the long-range atmospheric transport (LRAT) 
standard listed by Stockholm Convention ${ }^{11}$, they were recently observed in atmospheric particles in remote European and Canadian Arctic sites, ${ }^{12,}{ }^{13}$ as well as open oceans, such as Mediterranean, Black and North Seas, ${ }^{14,15}$ northern Pacific and Indian Ocean toward the polar regions, ${ }^{1}$ tropical and subtropical Atlantic, Pacific and Indian Oceans. ${ }^{16}$ These existing studies suggest that these compounds are capable of LRAT.

However, little research focused on the fate of OPEs in remote oceans. Similar to traditional POPs, the net flux of OPEs in the remote marine environment might be typically following the route of air-surface waters-deeper waters and then burial in the benthic sediments, where the deep ocean is seemed as the long-term oceanic repository for these chemicals. ${ }^{17,} 18$ OPEs have been detected in precipitation, indicating their atmospheric deposition processes. ${ }^{19}$, 20 For remote pelagic environments, such as the North Pacific and Arctic Oceans, they could be further transferred from well-mixed surface waters to deep waters as well as sediment through particle settling. Part of the particle settling could be driven by the 'biological pump', which is the settling fluxes of particle organic carbon associated with primary production by phytoplankton. ${ }^{17,} 21$ Previous research has observed positive relationship between concentrations of triphenyl phosphate (TPhP) and $d^{15} \mathrm{~N}$ in demersal species, indicating the transfer process of TPhP through particle settling to the bottom sediment and their further accumulation through the benthic food web. ${ }^{9}$

To examine the presence of OPEs in remote ocean sediment, this study presents the observation results of OPEs in surficial ocean sediment through transect from the 
North Pacific to the central Arctic Ocean (via the Bering Strait). Our aims were to investigate (i) the occurrence, latitudinal distribution and composition profile of OPEs in surficial sediment from remote ocean regions; (ii) contrast the presence of OPEs relative to PBDEs, established POPs, in these Arctic Ocean sediments, and (iii) derive a budget for OPEs in these remote sediment. Ultimately, our goal was to provide new insights into the fate and behavior of OPEs in the remote marine environment.

\section{Experimental Section}

\section{Sampling}

During the 4th Chinese National Arctic Research Expedition (CHINARE 4) held between July and September 2010, 0-2cm surficial marine sediment samples were collected onboard the ice-breaker R/V Xuelong ('Snow Dragon'). The sampling cruise generally covered a northward transect from the Bering Sea, through the Bering Strait to the Chukchi Sea, and across the Canada Basin and central Arctic Ocean $\left(53-88^{\circ} \mathrm{N}\right)$. Detailed information about the sampling work and the sediment samples are described in Supporting Information and listed in Table S1.

\section{Extraction, Analysis, QC/QA}

The extraction, purification and analysis were conducted in the clean laboratory of the Helmholtz-Zentrum Geesthacht (HZG) in Germany based on our previously published method, and is described in more detail in the Supporting Information. ${ }^{22}$ Briefly, approximately $10 \mathrm{~g}$ sediment sample was extracted with Soxhlet extractor, and then the extracts were rotary evaporated to $1-2 \mathrm{~mL}$, and further purified on a 
silica column. OPEs were analyzed using a gas chromatograph coupled to a triple quadrupole mass spectrometer operated in electron impact mode. Native OPE standards $d_{27}$-TnBP and $d_{15}-\mathrm{TPhP}$ were spiked to 3 solvent-extracted sediment samples as deuterated surrogate standards to check matrix effects. And ${ }^{13} \mathrm{C}_{6}-\mathrm{PCB} 208$ (Cambridge Isotope Laboratories) was added into the sample as injection standard. The recoveries of $d_{27}$-TnBP and $d_{15}$-TPhP in all sediment samples were $57 \pm 11 \%$ and $93 \pm 18 \%$, respectively. The recoveries of OPEs ranged from $95 \pm 2 \%$ for TiBP to 143 $\pm 7 \%$ for TCEP. Totally five procedural blanks were extracted, while the dominant OPE contaminations detected in the procedural blanks were $34 \pm 6 \mathrm{pg} / \mathrm{g}$ for TCPPs, $23 \pm 6 \mathrm{pg} / \mathrm{g}$ for TCEP and $18 \pm 3 \mathrm{pg} / \mathrm{g}$ for TPhP, respectively (Table S2). The method detection limits (MDLs), with a range from 1 to $53 \mathrm{pg} / \mathrm{g}$, were calculated by the average of procedural blanks plus three times the standard deviation $(3 \sigma)$ of procedural blanks. While the instrumental detection limits, ranging from 0.1 to $4 \mathrm{pg}$, were quantified as signal to noise ratio of 3.

\section{Results and Discussion}

\section{OPE Concentrations and Composition}

The total concentrations of 7 OPEs in the surface sediment $\left(\Sigma_{7} \mathrm{OPEs}\right.$, sum of the detected 4 non-halogenated OPEs and 3 halogenated OPEs) ranged from 159 to 4658 pg $\mathrm{g}^{-1}$ dry weight $(\mathrm{dw})$, with a mean of $878 \pm 892 \mathrm{pg} \mathrm{g}^{-1} \mathrm{dw}$. A summary of the chemical concentrations is presented in Table 1. Generally, the halogenated OPEs were more abundant than the non-halogenated OPEs and the composition profile of 
OPEs along all the sampling stations is shown in Figure 1-a. For halogenated OPEs, TCEP was the dominant compound which was detected at all sampling stations with a median contribution of $54 \pm 18 \%$ to $\Sigma_{7}$ OPEs. TCEP concentrations were in a range of 81 to $3903 \mathrm{pg} \mathrm{g}^{-1} \mathrm{dw}$. The second-most abundant chlorinated OPE, TCPPs (sum of three of isomers) ranged from 0.94 to $460 \mathrm{pg} \mathrm{g}^{-1} \mathrm{dw}$, followed by TDCP, which was detected in $63 \%$ samples with concentrations from not detected (n.d.) to $165 \mathrm{pg} \mathrm{g}^{-1} \mathrm{dw}$. Among the non-halogenated OPEs, TiBP was the dominant compound detected at all sampling stations, with a median contribution of $24 \pm 15 \%$ to $\Sigma_{7} \mathrm{OPEs}$ during the entire cruise. Individual TiBP concentrations ranged from 47 to $552 \mathrm{pg} \mathrm{g}^{-1} \mathrm{dw}$, followed by TnBP, which was also detected in all samples, for which concentrations ranged from 19 to $209 \mathrm{pg} \mathrm{g}^{-1} \mathrm{dw}$. The detection frequency for TPhP and TPeP was $77 \%$ and $83 \%$, with concentrations from n.d. to $105 \mathrm{pg} \mathrm{g}^{-1} \mathrm{dw}$ and n.d. to $81 \mathrm{pg} \mathrm{g}^{-1} \mathrm{dw}$, respectively.

OPEs were also investigated in airborne particles from East Asia to the remote Arctic regions during the same polar expedition CHINARE $4 .{ }^{1}$ Relatively higher levels of halogenated OPEs in comparison to non-halogenated OPEs, with the dominance of TCEP, in the surficial sediment was consistent with what was detected in the airborne particles of the same region. ${ }^{1}$ Similar results of the predominance of halogenated OPEs and TCEP were shown in the atmospheric observing stations located in the Canadian Arctic. ${ }^{13}$ Generally, halogenated OPEs display higher environmental persistence and historical production than non-halogenated OPEs. ${ }^{23}$ Moreover, it is reported that TCEP has gradually been replaced by the structurally similar TCPP in 
151 Europe due to the considerable carcinogenic and mutagenic effects. ${ }^{24}$ Relatively 152 higher detection frequency and levels of TCEP in our study might reflect its 153 continuing usage in Asia and North America. With a relatively high water solubility of $1547.0 \times 10^{3} \mathrm{mg} \mathrm{L}^{-1},{ }^{25}$ much higher levels of TCEP could be assumed to be present 155 dissolved in water bodies. However, for atmospheric particle phase samples collected 156 at Longyearbyen on Svalbard in the European Arctic, the sum of all non-halogenated 157 OPE concentrations comprised $\sim 75 \%$ of the $\Sigma$ OPE concentrations. ${ }^{12}$ And high levels 158 of non-halogenated OPEs, especially for TnBP and TiBP, were also observed in air 159 samples of Japan urbanized area. ${ }^{26}$ These indicated the existence of different 160 concentrations and sources of OPEs in varied regions.

There is little literature data on OPEs in the remote ocean sediment. We summarized 162 information on OPEs in estuary sediment and freshwater sediment in Table 2, together with the data of this research. OPE concentrations in urbanized locations such as in the shelf regions such as the Bering Strait (average value of 0.64\%) and Chukchi quite different from that of OPEs. And no significant relationships were discovered between any OPE compound and TOC ( $p>0.05$, Table S3). For PBDEs, we also 
173

174

175

discovered a lack of correlation between the contaminants and TOC. ${ }^{30}$ Thus TOC might not be a strong predictor for OPE concentrations in remote oceans.

\section{Geographic Distribution of OPEs}

The sampling stations were separated into five geographical regions as Bering Sea, Bering Strait, Chukchi Sea, Canadian Basin margin and Central Arctic Ocean to assess the spatial distribution of OPEs. Significant differences in the mean concentrations of OPEs were demonstrated among the five geographical regions according to analysis of variance (ANOVA). Figure 2 showed the spatial distribution of $\Sigma_{7} \mathrm{OPEs}$ along transect of the cruise. The highest average $\Sigma_{7} \mathrm{OPEs}$ concentrations were observed in the Central Arctic Ocean $\left(1463 \pm 1574 \mathrm{pg} \mathrm{g}^{-1} \mathrm{dw}\right)$, followed by sampling sites in the Bering Sea $\left(1207 \pm 593 \mathrm{pg} \mathrm{g}^{-1} \mathrm{dw}\right)$ and Canadian Basin margin region $\left(1035 \pm 491 \mathrm{pg} \mathrm{g}^{-1} \mathrm{dw}\right)$, however, the Chukchi Sea $\left(468 \pm 219 \mathrm{pg} \mathrm{g}^{-1} \mathrm{dw}\right)$ and Bering Strait $\left(350 \pm 59 \mathrm{pg} \mathrm{g}^{-1} \mathrm{dw}\right)$ had relatively lower average concentrations. Except for the Bering Sea, $\Sigma_{7} \mathrm{OPEs}$ concentrations generally increased with the increasing latitudes from Bering Strait to the Central Arctic Ocean. Beyond these regional differences we also note that concentrations of $\Sigma_{7} \mathrm{OPEs}$ showed spatial variability in the Central Arctic Ocean. Elevated $\Sigma_{7}$ OPEs levels were observed at sites BN06 (4658 $\mathrm{pg} \mathrm{g}^{-1} \mathrm{dw}$ ) and BN04 (2360 $\mathrm{pg} \mathrm{g}^{-1} \mathrm{dw}$ ), as well as the northern most site BN13 (1144 $\mathrm{pg} \mathrm{g}^{-1} \mathrm{dw}$ ). Notably high $\Sigma_{7} \mathrm{OPEs}$ concentrations were also shown at site B04 (2093 pg $\mathrm{g}^{-1} \mathrm{dw}$ ) in the Bering Sea, as well as site MS02 (1855 $\left.\mathrm{pg} \mathrm{g}^{-1} \mathrm{dw}\right)$ in the Canadian Basin margin area, respectively. Moreover, for OPEs composition profile in the five 
different geographic areas, we observed that the contributions of halogenated OPEs (typically TCEP and TCPP) to total OPE profile increased from Bering Strait to the Central Arctic Ocean. In contrast, the contributions of non-halogenated OPEs (typically TiBP and TnBP) decreased from Bering Strait to the Central Arctic Ocean (Figure 1-b).

For the distribution of OPEs in airborne particles from East Asia to the remote Arctic, the highest concentrations were observed in the Sea of Japan, while the concentrations decreased dramatically to the open North Pacific Ocean. ${ }^{1}$ The high OPE levels shown in East Asia were attributed to their release in Asian countries, such as production and usage of OPEs in factories as well as the treatment of e-waste. Although we do not have data about OPE concentrations in sediment of East Asia area, the relatively high level of OPEs in the sediment of Bering Sea might partly share these Asian sources followed by atmospheric deposition and further settling through water column.

Moreover, Möller et al. (2012) reported some high atmospheric OPE concentrations with-in the Arctic were due to air masses from continent of Russia and Alaska. For our surficial sediments observations, OPE concentrations generally increased with the increasing latitudes from Bering Strait to the Central Arctic Ocean, though highest overall OPE concentrations were not found at the northern most sampling site. This suggests that factors other than LRAT and 'cold condensation effect' affect OPEs, possibly indicating the existence of some with-in Arctic sources. ${ }^{31}$

In general, high concentrations of OPEs in high latitude regions were due to halogenated OPEs rather than non-halogenated OPEs. Some high concentrations of 
halogenated OPEs, typically TCEP and TCPP were displayed at Station BN06, BN04 and MS02 (Figure 2). Higher concentrations of halogenated OPEs were also observed around the river mouth of the Canadian Arctic close to Canadian Archipelago and Sühring et al. attributed it to river discharge. ${ }^{13}$ Generally, halogenated OPEs possess higher water solubility compared to non-halogenated OPEs. And the characteristic travel distance of most halogenated OPEs was longer in water than in air. ${ }^{32}$ In our study, the stations displayed relatively higher concentrations of halogenated OPEs at Canadian Basin margin and Central Arctic Ocean were quite close to the Beaufort Gyre. Seawater circulated in the Beaufort Sea was mainly through Canadian Archipelago and further transported to the remote Arctic. Therefore these stations with relatively high levels of halogenated OPEs might also share the source of river discharge of Canadian Arctic to a certain extent.

\section{Observations of Latitudinal Fractionation}

To assess the influence of volatility on the LRAT potential of the individual OPE compound, the ratio of individual OPE concentrations at northern most $88^{\circ} \mathrm{N}$ (high Arctic station BN13) and their concentration at $61^{\circ} \mathrm{N}$ (Bering Strait station B14) as a function of log subcooled liquid vapor pressure (pL) was obtained (Figure S1; TPeP was excluded for which pL was not known from the same literature source; TDCP was excluded as well because it was not detected at these two stations). ${ }^{3}$ Distributions of various polychlorinated biphenyl congeners (PCBs) between northern and southern regions have been shown to strongly correlation with $\mathrm{pL} \cdot{ }^{33}$ It was thus a potentially 
valuable tool to gauge the compounds' propensity for LRAT to the Arctic. ${ }^{34}$ No strong relationship was detected between increasing North/South ratio and pL for these five OPE compounds (Figure S1-a), but a strong correlation was shown if the more reactive TnBP and TiBP were excluded (Figure S1-b). The North/South ratios for both TnBP and TiBP were $<1$ in our surficial sediment samples, implying they degrade during transport to the Arctic. Actually, TnBP and TiBP displayed high atmospheric concentrations in urbanized regions, ${ }^{26}$ however their concentrations were quite low in remote Arctic atmospheric samples. ${ }^{1}$ This indicated that non-halogenated OPEs, in particular TnBP and TiBP were heavily emitted to the atmosphere within urbanized regions, but they might be further degraded and/or trapped in soil/sediment during atmospheric transport. Moreover, decreasing contributions of both TnBP and TiBP to total investigated OPEs were observed in our surficial sediments from Bring Strait through Chukchi Sea to the Canadian Basin and central Arctic Ocean (Figure 1-b). This further demonstrated that they have relatively low potential of being transported to the remote Arctic regions. In contrast, the North/South ratios for TCEP and TCPP were $>1(\sim 8$ and $\sim 3)$ in our sediment samples. The strong relationship between North/South ratio and volatility together with their increasing contributions from low to high latitudes (Figure 1-b) demonstrated high potential of being transported to remote oceans for TCEP and TCPP.

Moreover, Kow is also used to investigate the relation with increasing North/South ratio. The results showed that there was a strong negative relationship between North/South ratio and $\operatorname{logKow}$ value (Figure S2). These again demonstrated that the 
compound with high value of Kow, such as TiBP and TnBP, have relatively low potential of being transported to the Arctic Ocean (the North/South concentration ratio $<1)$. And they might be trapped in the ocean sediment of low latitude regions during their transport from low latitude to high latitude regions. In contrast, the contaminants with relative low value of Kow, such as TCEP and TCPP, have relatively higher potential of being transported to remote oceans (the North/South concentration ratio $>1$ ). And sediments in the remote Arctic could be seemed as their final sink.

\section{Budget of OPEs in the Central Arctic Ocean Basin}

Since this work regularly observed OPE concentrations in remote Arctic Ocean surficial sediment, we were interested in deriving a mass budget of this reservoir. Considering the relatively low sedimentation rates, at about $1 \sim 2 \mathrm{~cm} / \mathrm{kyr}$ in the central Arctic Ocean, ${ }^{35,36}$ the sediment samples (top $2 \mathrm{~cm}$ ) would have captured all of the industrial production since OPEs were produced. Therefore using the surficial sediment OPE concentrations obtained over Canada Basin and central Arctic Ocean, we estimated the inventories of OPEs in the sediment of the Central Arctic Ocean Basin. Any dilution through bioturbation will mean that our budget is an underestimation of total OPE masses stored in these remote sediments.

The method we used is as previously reported; a detailed calculation method is provided in supporting information. ${ }^{37}$ The estimation results are shown in Table 3. Generally, for halogenated OPEs, the budget of the dominant TCEP to the Central 
Arctic Ocean Basin was estimated in the range of 12-219 tons, with a median value of 39 tons. While for non-halogenated OPEs, the dominant TiBP budget was estimated in the ranges of 3.6-16 tons, with a median value of 6.2 tons. Compared with thousands tons of production/usage volumes of TCEP per year in Europe and United States, ${ }^{23}$ the input to the Arctic Ocean sediment represented still a very small amount.

\section{Comparison of OPEs in Surficial Sediment with PBDEs}

Since OPEs are used in many cases as substitutes of PBDEs, OPE concentrations are compared with PBDE concentrations observed in surficial sediment in the same research region during CHINARE 3, CHINARE 4 and 5 campaign. Concentrations of the most dominant PBDEs (BDE47, -99, -153, and -209) are given in Table S4 and comparison between dominant OPEs and PBDEs along northern latitude is shown in Figure 3. The data available showed that BDE-47, -99 and -153 were generally in the range of tens $\mathrm{pg} \mathrm{g}^{-1} \mathrm{dw}$, while BDE-209 were in hundreds $\mathrm{pg} \mathrm{g}^{-1} \mathrm{dw}$ range. Moreover, the PBDEs (excluding BDE-209) concentrations generally decreased from 2008 to 2012, especially in the Bering Sea, Bering Strait, and Chukchi Sea area, although this temporal trend might not be so significant considering different analytical methods and sampling sites among these cruises..$^{30,38}$

In comparison, concentrations of the dominant OPEs (TiBP and TCEP) in the surficial sediment are in the hundreds to thousands $\mathrm{pg} \mathrm{g}^{-1} \mathrm{dw}$ range (as data displayed in Table 1), already greater than key PBDEs. Concentrations of the other detected OPEs were generally comparable to or greater than BDE47, $-99,-153$, but lower than BDE-209. 
Therefore the transport and fluxes of TCEP and TiBP to benthic sediment of the marine environment already exceed those of PBDEs. Similarly, higher concentrations of OPEs were observed in atmospheric particles at Polar Regions compared with concentrations of PBDEs. ${ }^{1,12,13}$

From our results, the remote marine sediments could be seemed as a great repository for OPEs, especially in the Arctic regions. Given the increasing production and usage of OPEs as substitutes of PBDEs, OPEs will continue to be emitted to the atmosphere, and transferred into the surface waters, and further transported to the deep water and sediment of the remote marine environment. And these sediments likely constitute OPEs' long term global sink. Given current sediment concentrations, OPEs are more efficiently transported to remote Arctic sediments than PBDEs.

Supporting Information. Details on the sampling and lab analysis information, PBDE concentrations, along with calculation method of OPE inventories. This material is available free of charge via the Internet at http://pubs.acs.org.

Acknowledgements. We would like to appreciate staff of the $4^{\text {th }}$ Chinese National Arctic Research Expedition. The research is supported by Youth Fund of National Natural Science Foundation of China (41506215), Shanghai Sailing Program (15YF1405100) and Science and Technology Development Fund of Shanghai Ocean University (A2-0209-15-200001). The samples were obtained from Polar Sediment Sample Chamber of China. The sample analysis was supported by the General 


\section{References}

1. Moller, A.; Sturm, R.; Xie, Z. Y.; Cai, M. H.; He, J. F.; Ebinghaus, R., Organophosphorus Flame Retardants and Plasticizers in Airborne Particles over the Northern Pacific and Indian Ocean toward the Polar Regions: Evidence for Global Occurrence. Environ Sci Technol 2012, 46, (6), 3127-3134. 2. Marklund, A.; Andersson, B.; Haglund, P., Screening of organophosphorus compounds and their distribution in various indoor environments. Chemosphere 2003, 53, (9), 1137-1146.

3. Reemtsma, T.; Quintana, J. B.; Rodil, R.; Garcia-Lopez, M.; Rodriguez, I., Organophosphorus flame retardants and plasticizers in water and air I. Occurrence and fate. Trac-Trends in Analytical Chemistry 2008, 27, (9), 727-737.

4. Global and China Flame Retardant Industry Report, 2014-2016; Research In China at China Market Research Report: 2016.

5. Bollmann, U. E.; Moler, A.; Xie, Z. Y.; Ebinghaus, R.; Einax, J. W., Occurrence and fate of organophosphorus flame retardants and plasticizers in coastal and marine surface waters. Water Research 2012, 46, (2), 531-538.

6. Wang, R. M.; Tang, J. H.; Xie, Z. Y.; Mi, W. Y.; Chen, Y. J.; Wolschke, H.; Tian, C. G.; Pan, X. H.; Luo, Y. M.; Ebinghaus, R., Occurrence and spatial distribution of organophosphate ester flame retardants and plasticizers in 40 rivers draining into the Bohai Sea, north China. Environ Pollut 2015, 198, 172-178. 7. Chung, H. W.; Ding, W. H., Determination of organophosphate flame retardants in sediments by microwave-assisted extraction and gas chromatography-mass spectrometry with electron impact and chemical ionization. Anal Bioanal Chem 2009, 395, (7), 2325-2334.

8. Cao, S. X.; Zeng, X. Y.; Song, H.; Li, H. R.; Yu, Z. Q.; Sheng, G. Y.; Fu, J. M., Levels and distributions of organophosphate flame retardants and plasticizers in sediment from Taihu Lake, China. Environ Toxicol Chem 2012, 31, (7), 1478-1484.

9. Kim, J. W.; Isobe, T.; Chang, K. H.; Amano, A.; Maneja, R. H.; Zamora, P. B.; Siringan, F. P.; Tanabe, S., Levels and distribution of organophosphorus flame retardants and plasticizers in fishes from Manila Bay, the Philippines. Environ Pollut 2011, 159, (12), 3653-3659.

10. Sundkvist, A. M.; Olofsson, U.; Haglund, P., Organophosphorus flame retardants and plasticizers in marine and fresh water biota and in human milk. Journal of Environmental Monitoring 2010, 12, (4), 943-951.

11. Zhang, X.; Suehring, R.; Serodio, D.; Bonnell, M.; Sundin, N.; Diamond, M. L., Novel flame retardants: Estimating the physical-chemical properties and environmental fate of 94 halogenated and organophosphate PBDE replacements. Chemosphere 2016, 144, 2401-2407.

12. Salamova, A.; Hermanson, M. H.; Hites, R. A., Organophosphate and Halogenated Flame Retardants in Atmospheric Particles from a European Arctic Site. Environ Sci Technol 2014, 48, (11), 6133-6140.

13. Suhring, R.; Diamond, M. L.; Scheringer, M.; Wong, F.; Pucko, M.; Stern, G.; Burt, A.; Hung, H.; Fellin, P.; Li, H.; Jantunen, L. M., Organophosphate Esters in Canadian Arctic Air: Occurrence, Levels 
and Trends. Environ Sci Technol 2016, 50, (14), 7409-7415.

14. Castro-Jimenez, J.; Berrojalbiz, N.; Pizarro, M.; Dachs, J., Organophosphate Ester (OPE) Flame Retardants and Plasticizers in the Open Mediterranean and Black Seas Atmosphere. Environ Sci Technol 2014, 48, (6), 3203-3209.

15. Moller, A.; Xie, Z. Y.; Caba, A.; Sturm, R.; Ebinghaus, R., Organophosphorus flame retardants and plasticizers in the atmosphere of the North Sea. Environ Pollut 2011, 159, (12), 3660-3665.

16. Castro Jimenez, J.; Gonzalez-Gaya, B.; Pizarro, M.; Casal, P.; Pizarro-Alvarez, C.; Dachs, J., ORGANOPHOSPHATE ESTER FLAME RETARDANTS AND PLASTICIZERS IN THE GLOBAL OCEANIC ATMOSPHERE. Environ Sci Technol 2016.

17. Dachs, J.; Lohmann, R.; Ockenden, W. A.; Mejanelle, L.; Eisenreich, S. J.; Jones, K. C., Oceanic biogeochemical controls on global dynamics of persistent organic pollutants. Environ Sci Technol 2002, 36, (20), 4229-4237.

18. Jaward, F. M.; Barber, J. L.; Booij, K.; Dachs, J.; Lohmann, R.; Jones, K. C., Evidence for dynamic air-water coupling and cycling of persistent organic pollutants over the open Atlantic Ocean. Environ Sci Technol 2004, 38, (9), 2617-2625.

19. Regnery, J.; Puttmann, W., Organophosphorus Flame Retardants and Plasticizers in Rain and Snow from Middle Germany. Clean-Soil Air Water 2009, 37, (4-5), 334-342.

20. Regnery, J.; Puttmann, W., Seasonal fluctuations of organophosphate concentrations in precipitation and storm water runoff. Chemosphere 2010, 78, (8), 958-964.

21. Dachs, J.; Eisenreich, S. J.; Baker, J. E.; Ko, F. C.; Jeremiason, J. D., Coupling of phytoplankton uptake and air-water exchange of persistent organic pollutants. Environ Sci Technol 1999, 33, (20), 3653-3660.

22. Chen, W.-L.; Xie, Z.; Wolschke, H.; Gandrass, J.; Koetke, D.; Winkelmann, M.; Ebinghaus, R., Quantitative determination of ultra-trace carbazoles in sediments in the coastal environment. Chemosphere 2016, 150, 586-595.

23. van der Veen, I.; de Boer, J., Phosphorus flame retardants: Properties, production, environmental occurrence, toxicity and analysis. Chemosphere 2012, 88, (10), 1119-1153.

24. Stachel, B.; Jantzen, E.; Knoth, W.; Kruger, F.; Lepom, P.; Oetken, M.; Reincke, H.; Sawal, G.; Schwartz, R.; Uhlig, S., The Elbe flood in August 2002 - Organic contaminants in sediment samples taken after the flood event. J Environ Sci Heal A 2005, 40, (2), 265-287.

25. Fisk, P. R.; Girling, A. E.; Wildey, R. J., Prioritisation of Flame Retardants for Environmental Risk Assessment. In Agency, E., Ed. United Kingdom, 2003.

26. Ohura, T.; Amagai, T.; Senga, Y.; Fusaya, M., Organic air pollutants inside and outside residences in Shimizu, Japan: Levels, sources and risks. Sci Total Environ 2006, 366, (2-3), 485-499.

27. Martinez-Carballo, E.; Gonzalez-Barreiro, C.; Sitka, A.; Scharf, S.; Gans, O., Determination of selected organophosphate esters in the aquatic environment of Austria. Sci Total Environ 2007, 388, (1-3), 290-299.

28. Leonards, P.; Steindal, E. H.; van der Veen, I.; Berg, V.; Bustnes, J. O.; van Leeuwen, S. Screening of Organophosphor Flame Retardants 2010; 2011.

29. Garcia-Lopez, M.; Rodriguez, I.; Cela, R., Pressurized liquid extraction of organophosphate triesters from sediment samples using aqueous solutions. Journal of Chromatography A 2009, 1216, (42), 6986-6993.

30. Ma, Y. X.; Halsall, C. J.; Crosse, J. D.; Graf, C.; Cai, M. H.; He, J. F.; Gao, G. P.; Jones, K., Persistent organic pollutants in ocean sediments from the North Pacific to the Arctic Ocean. Journal of 
Geophysical Research-Oceans 2015, 120, (4), 2723-2735.

31. Wania, F.; Mackay, D., Global Fractionation and Cold Condensation of Low Volatility Organochlorine Compounds in Polar-Regions. Ambio 1993, 22, (1), 10-18.

32. Cristale, J.; Katsoyiannis, A.; Chen, C. E.; Jones, K. C.; Lacorte, S., Assessment of flame retardants in river water using a ceramic dosimeter passive sampler. Environ Pollut 2013, 172, 163-169.

33. Sun, C. X.; Soltwedel, T.; Bauerfeind, E.; Adelman, D. A.; Lohmann, R., Depth Profiles of Persistent Organic Pollutants in the North and Tropical Atlantic Ocean. Environ Sci Technol 2016, 50, (12), 6172-6179.

34. Sobek, A.; Gustafsson, O., Latitudinal fractionation of polychlorinated biphenyls in surface seawater along a 62 degrees $\mathrm{N}-89$ degrees $\mathrm{N}$ transect from the southern Norwegian Sea to the North Pole area. Environ Sci Technol 2004, 38, (10), 2746-2751.

35. Backman, J.; Jakobsson, M.; Lovlie, R.; Polyak, L.; Febo, L. A., Is the central Arctic Ocean a sediment starved basin? Quaternary Sci Rev 2004, 23, (11-13), 1435-1454. 36. Darby, D. A.; Ortiz, J.; Polyak, L.; Lund, S.; Jakobsson, M.; Woodgate, R. A., The role of currents and sea ice in both slowly deposited central Arctic and rapidly deposited Chukchi-Alaskan margin sediments. Global Planet Change 2009, 68, (1-2), 56-70. 37. Jonsson, A.; Gustafsson, O.; Axelman, J.; Sundberg, H., Global accounting of PCBs in the continental shelf sediments. Environ Sci Technol 2003, 37, (2), 245-255.

38. Cai, M. G.; Hong, Q. Q.; Wang, Y.; Luo, X. J.; Chen, S. J.; Cai, M. H.; Qiu, C. R.; Huang, S. Y.; Mai, B. X., Distribution of polybrominated diphenyl ethers and decabromodiphenylethane in surface sediments from the Bering Sea, Chukchi Sea, and Canada Basin. Deep-Sea Res Pt li 2012, 81-84, 95-101. 


\section{Figure Captions}

437 Figure 1. Composition profile of observed OPEs in surficial marine sediments along the sampling transect (a); Average contributions of investigated OPEs in the five geographical regions (b)

440

441

Figure 2. Spatial distributions of OPEs in the surface marine sediment along the sampling cruise

442 443

Figure 3. Comparison between dominant OPEs and PBDEs in surface marine sediment along northern latitude 

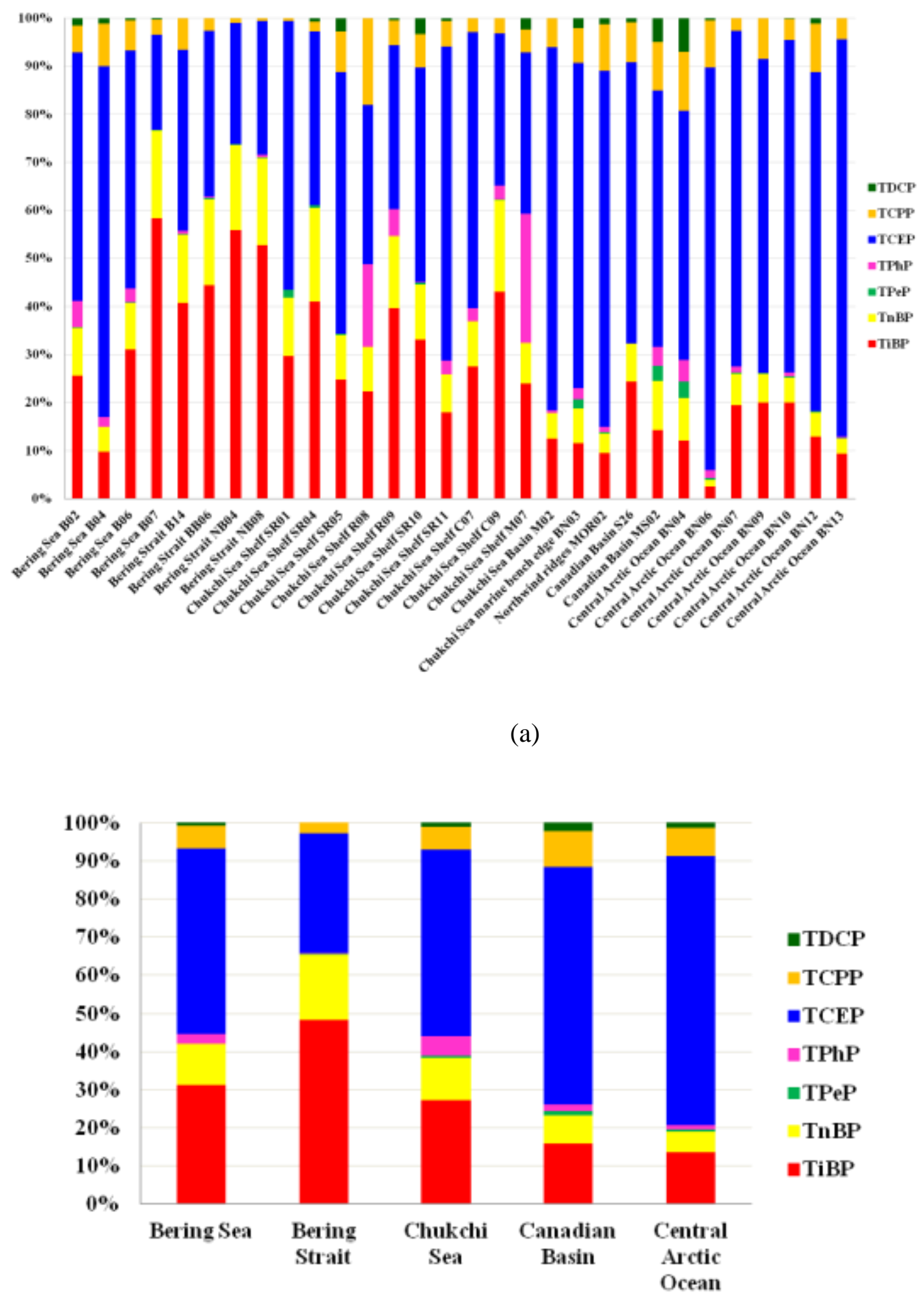


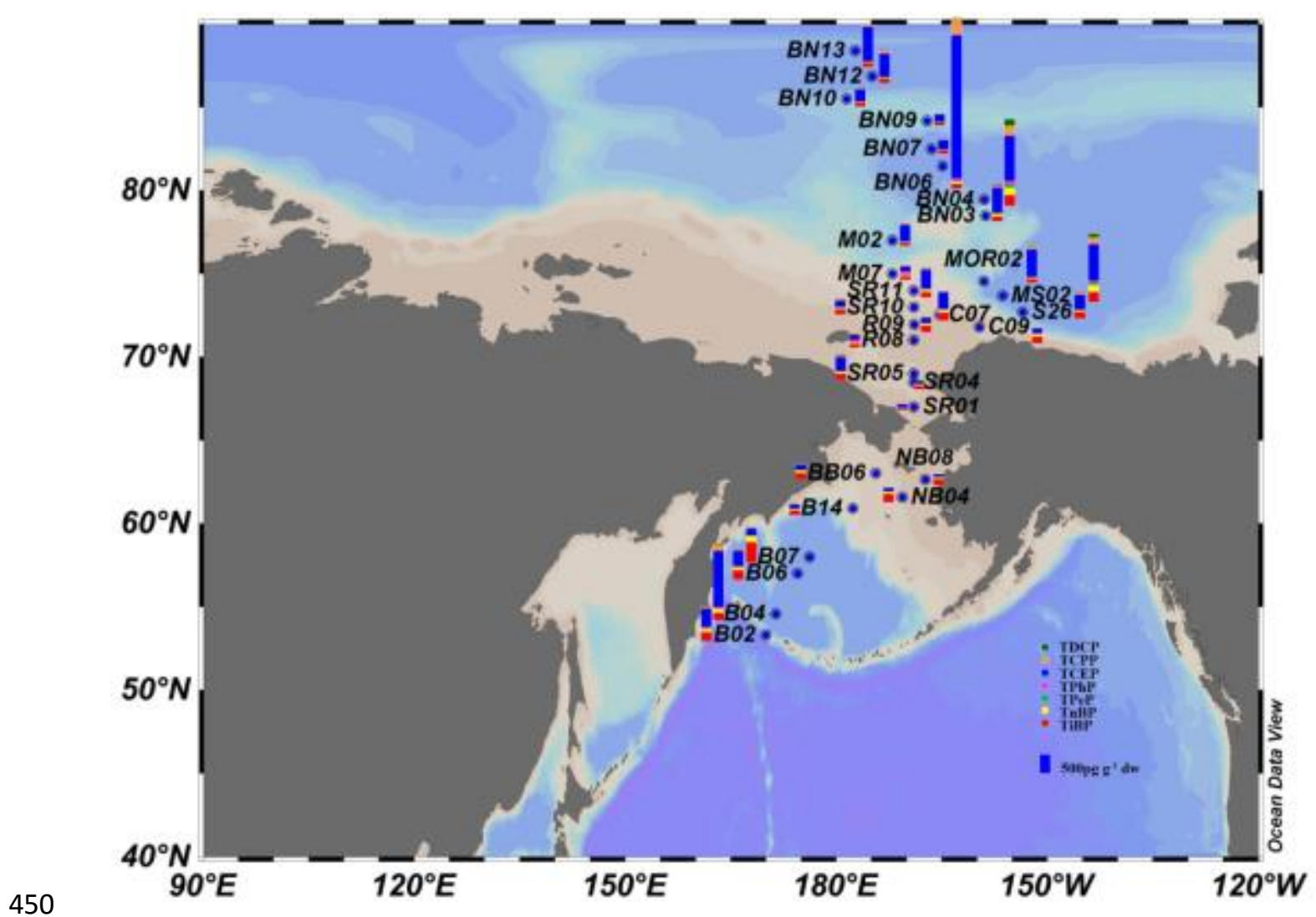

$451 \quad$ Figure 2

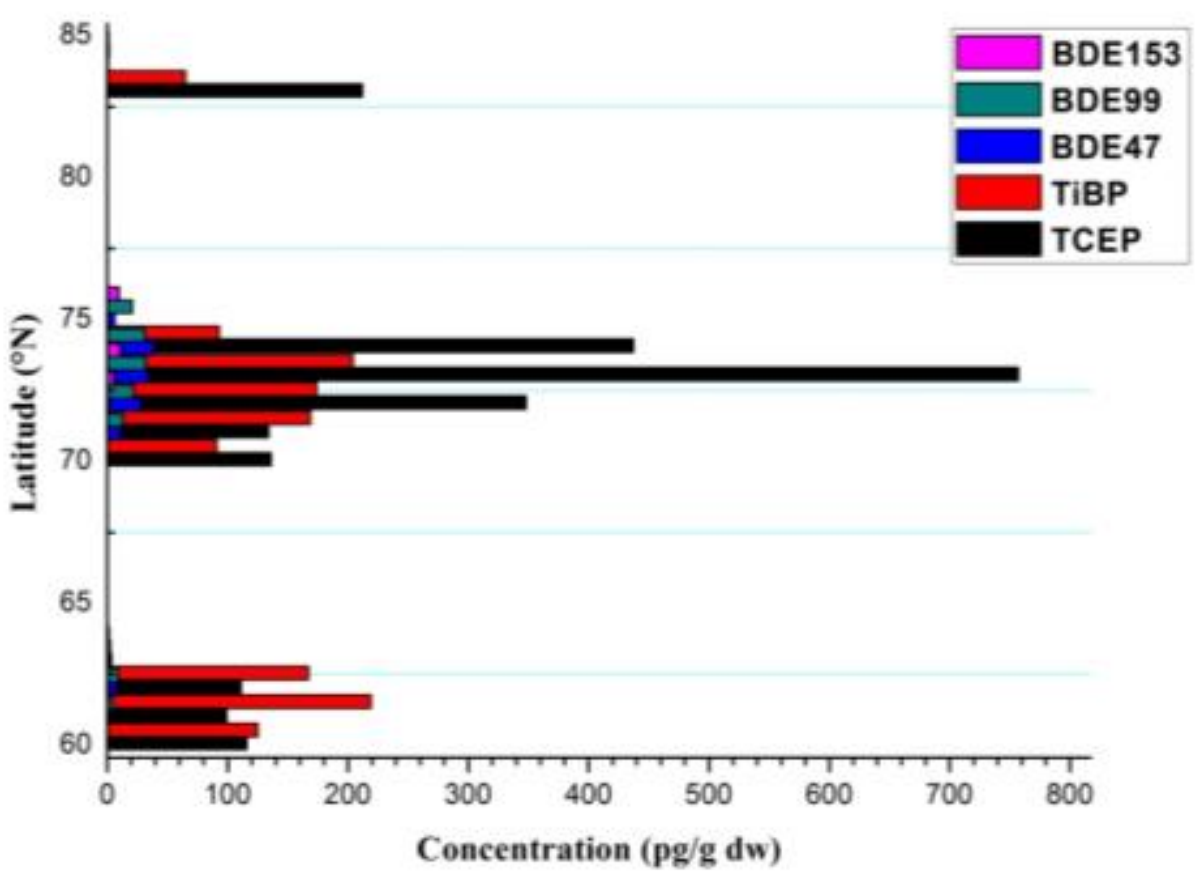

Figure 3 
Table 1. Individual concentrations of OPEs in the surface sediment ( $\mathrm{pg} \mathrm{g}^{-1}$ d.w.) at 456 sampling sites from Bering Sea to the Central Arctic Ocean (n.d. = not detected)

\begin{tabular}{|c|c|c|c|c|c|c|c|c|c|c|c|c|}
\hline Location & Site & TiBP & TnBP & TPeP & TPhP & TCPP-1 & TCPP-2 & TCPP-3 & Sum of TCPPs & TCEP & TDCP & Sum \\
\hline Bering Sea & B02 & 244 & 95 & 2.0 & 51 & 40 & 13 & 0.67 & 54 & 493 & 14 & 954 \\
\hline Bering Sea & B04 & 204 & 108 & 0.65 & 44 & 146 & 37 & 3.5 & 186 & 1527 & 24 & 2093 \\
\hline Bering Sea & B06 & 260 & 80 & 2.1 & 23 & 42 & 8.6 & 1.3 & 52 & 415 & 3.7 & 836 \\
\hline Bering Sea & B07 & 552 & 173 & 2.0 & n.d. & 24 & 6.0 & 1.1 & 31 & 186 & 2.4 & 947 \\
\hline Average & & 315 & 114 & 1.7 & 30 & 63 & 16 & 1.6 & 81 & 655 & 11 & 1207 \\
\hline Bering Strait & B14 & 125 & 43 & 0.58 & 2.1 & 17 & 3.8 & n.d. & 20 & 116 & n.d. & 308 \\
\hline Bering Strait & BB06 & 181 & 73 & 1.1 & 1.2 & 9.4 & 1.4 & n.d. & 11 & 141 & n.d. & 408 \\
\hline Bering Strait & NB04 & 219 & 70 & 0.27 & n.d. & 3.5 & 0.64 & n.d. & 4.2 & 99 & n.d. & 391 \\
\hline Bering Strait & NB08 & 154 & 53 & 0.42 & 1.9 & 1.8 & 0.12 & n.d. & 1.9 & 81 & n.d. & 292 \\
\hline Average & & 170 & 60 & 0.60 & 1.3 & 7.8 & 1.5 & n.d. & 9.3 & 109 & n.d. & 350 \\
\hline Chukchi Sea Shelf & SR01 & 47 & 19 & 2.7 & n.d. & 0.94 & n.d. & n.d. & 0.94 & 89 & n.d. & 159 \\
\hline Chukchi Sea Shelf & SR04 & 94 & 45 & 1.1 & n.d. & 2.8 & 2.0 & n.d. & 4.9 & 83 & 1.6 & 228 \\
\hline Chukchi Sea Shelf & SR05 & 171 & 65 & 1.6 & n.d. & 46 & 11 & 1.5 & 59 & 376 & 19 & 690 \\
\hline Chukchi Sea Shelf & R08 & 91 & 38 & 0.075 & 71 & 61 & 12 & 0.80 & 74 & 136 & n.d. & 410 \\
\hline Chukchi Sea Shelf & R09 & 160 & 61 & n.d. & 23 & 17 & 3.8 & n.d. & 21 & 138 & 2.0 & 404 \\
\hline Chukchi Sea Shelf & SR10 & 136 & 47 & 1.6 & 0.86 & 22 & 6.1 & 0.52 & 29 & 183 & 14 & 411 \\
\hline Chukchi Sea Shelf & SR11 & 144 & 63 & n.d. & 23 & 35 & 7.4 & 0.22 & 42 & 523 & 4.6 & 800 \\
\hline Chukchi Sea Shelf & C07 & 215 & 73 & 0.59 & 21 & 18 & 4.2 & 0.94 & 23 & 449 & 0.53 & 782 \\
\hline Chukchi Sea Shelf & C09 & 178 & 79 & 0.14 & 12 & 10 & 3.3 & n.d. & 13 & 131 & n.d. & 413 \\
\hline Chukchi Sea Shelf & M07 & 91 & 32 & n.d. & 102 & 17 & 1.9 & n.d. & 19 & 127 & 8.8 & 381 \\
\hline Chukchi Sea Basin & M02 & 76 & 33 & n.d. & 3.1 & 29 & 7.7 & 0.29 & 37 & 461 & n.d. & 610 \\
\hline Chukchi Sea marine bench edge & BN03 & 116 & 71 & 19 & 23 & 56 & 15 & 1.1 & 72 & 676 & 21 & 998 \\
\hline Average & & 126 & 52 & 2.3 & 23 & 26 & 6.2 & 0.45 & 33 & 281 & 5.9 & 524 \\
\hline Northwind ridges & MOR02 & 95 & 41 & 2.9 & 11 & 73 & 23 & 2.1 & 98 & 747 & 12 & 1007 \\
\hline Canadian Basin & MS02 & 265 & 189 & 58 & 74 & 143 & 40 & 3.5 & 186 & 990 & 92 & 1855 \\
\hline Canadian Basin & S26 & 172 & 56 & n.d. & n.d. & 48 & 10 & 1.1 & 59 & 413 & 6.0 & 706 \\
\hline Average & & 177 & 95 & 20 & 28 & 88 & 24 & 2.3 & 114 & 717 & 37 & 1190 \\
\hline Central Arctic Ocean & BN04 & 286 & 209 & 81 & 105 & 218 & 67 & 6.4 & 291 & 1223 & 165 & 2360 \\
\hline Central Arctic Ocean & BN06 & 117 & 66 & 17 & 76 & 335 & 112 & 13 & 460 & 3903 & 18 & 4658 \\
\hline Central Arctic Ocean & BN07 & 74 & 25 & 1.0 & 4.9 & 7.3 & 2.8 & 0.13 & 10 & 268 & n.d. & 383 \\
\hline Central Arctic Ocean & BN09 & 65 & 20 & 0.31 & n.d. & 23 & 4.2 & 0.014 & 27 & 212 & n.d. & 323 \\
\hline Central Arctic Ocean & BN10 & 97 & 25 & 0.75 & 4.2 & 14 & 6.3 & n.d. & 21 & 335 & 1.2 & 483 \\
\hline Central Arctic Ocean & BN12 & 115 & 45 & 2.6 & 0.28 & 70 & 18 & 1.2 & 89 & 630 & 10 & 891 \\
\hline Central Arctic Ocean & BN13 & 107 & 36 & 0.61 & 4.5 & 40 & 10 & 0.32 & 51 & 945 & n.d. & 1144 \\
\hline Average & & 123 & 61 & 15 & 28 & 101 & 32 & 3.0 & 136 & 1073 & 28 & 1463 \\
\hline Average of the cruise & & 162 & 68 & 6.7 & 23 & 52 & 15 & 1.3 & 68 & 536 & 14 & 878 \\
\hline
\end{tabular}

457

458

459

460

Table 2. Comparison of OPE concentration ranges ( $\mathrm{pg} \mathrm{g}^{-1}$ d.w.) in surface sediment during CHINARE 4 with present literature data

\begin{tabular}{|c|c|c|c|c|c|}
\hline Location & TCPP & TCEP & TDCP & TPhP & Reference \\
\hline Bering Sea & $31-186(53)$ & $186-1527(454)$ & $2.4-24(9.1)$ & n.d.-51 (33) & this study \\
\hline Bering Strait & $1.9-20(7.5)$ & $81-141(107)$ & n.d. & n.d.-2.1 (1.5) & this study \\
\hline Chukchi Sea & $0.94-74(26)$ & $83-676(160)$ & n.d.-21 (1.8) & n.d.-102 (17) & this study \\
\hline Canadian Basin margin & $59-186(98)$ & 413-990 (747) & $6.0-92(12)$ & n.d.-74 (11) & this study \\
\hline Central Arctic Ocean & $10-460(51)$ & $212-3903(630)$ & n.d.-165 (1.2) & n.d.-105 (4.5) & this study \\
\hline Taihu lake (China) & n.d. $-2270(1360)$ & $620-3170(1750)$ & n.d.-5540 (1300) & n.d.-1190 (490) & $\operatorname{ref}^{6}$ \\
\hline River Danube (Austria) & $<610-20000$ & n.d. $-<7700$ & n.d. & n.d. $-<790$ & $\operatorname{ref}^{22}$ \\
\hline River Schwechat (Austria) & 1300000 & 160000 & $<640$ & 160000 & $\mathrm{ref}^{22}$ \\
\hline River Liesig (Austria) & 95000 & n.d. & $<640$ & 4300 & $\mathrm{ref}^{22}$ \\
\hline Kåfjorden, Trondheim, Oslo, Mjøsa (Norway) & $<150-54000$ & $<160-8500$ & $<90-1000$ & $<100-6800$ & $\mathrm{ref}^{23}$ \\
\hline Rivers and marine estuaries of Galicia (Spain) & 38000 & 45900 & n.d. & n.a. & $\mathrm{ref}^{24}$ \\
\hline River at Chung-Li and coastal region at Tai-shi and Chi-ku (Taiwan) & n.d. -9500 & n.d. -1500 & n.d. -1100 & n.d. -3100 & $\operatorname{ref}^{5}$ \\
\hline
\end{tabular}

462 Average concentrations are given in brackets

463 n.d. $=$ not detected

464

n.a. $=$ not analyzed 
467 Table 3. Estimation results of the inventories of OPEs in the sediment for the Central 468 Arctic Ocean Basin (tons)

\begin{tabular}{rlrrrr}
\hline & min & max & median & average \\
\hline TiBP & 3.6 & 16 & 6.2 & 7.8 \\
TnBP & 1.1 & 12 & 2.4 & 4.0 \\
TPeP & 0 & 4.6 & 0.10 & 0.93 \\
& TPhP & 0 & 5.9 & 0.27 & 1.6 \\
& TCPP & 0.57 & 26 & 4.2 & 7.3 \\
& TCEP & 12 & 219 & 39 & 54 \\
& TDCP & 0 & 9.2 & 0.45 & 1.7 \\
469 & Total & 17 & 292 & 52 & 78 \\
\hline
\end{tabular}

